\title{
Rede no Rio:dominação e indignação
}

Network in Rio: domination and indignation

Red en Río: dominación e indignación

Réseaux à Rio: domination et indignation

Tamara Tania Cohen Egler, Fabiana Mabel de Oliveira e Lucas Trajano

\section{(2) OpenEdition}

\section{Journals}

\section{Edição electrónica}

URL: http://journals.openedition.org/espacoeconomia/1089

DOI: 10.4000/espacoeconomia.1089

ISSN: 2317-7837

\section{Editora}

Núcleo de Pesquisa Espaço \& Economia

\section{Refêrencia eletrónica}

Tamara Tania Cohen Egler, Fabiana Mabel de Oliveira e Lucas Trajano, « Rede no Rio:dominação e indignação », Espaço e Economia [Online], 5 | 2014, posto online no dia 16 dezembro 2014, consultado o 11 junho 2020. URL : http://journals.openedition.org/espacoeconomia/1089 ; DOI : https://doi.org/ 10.4000/espacoeconomia.1089

Este documento foi criado de forma automática no dia 11 junho 2020.

(C) NUPEE 


\title{
Rede no Rio:dominação e indignação
}

\author{
Network in Rio: domination and indignation \\ Red en Río: dominación e indignación \\ Réseaux à Rio: domination et indignation
}

Tamara Tania Cohen Egler, Fabiana Mabel de Oliveira e Lucas Trajano

\section{Introdução}

1 O ponto de partida teórico considera a ação como categoria central da política. Serão examinadas três categorias: a primeira está associada aos atores; a segunda, aos processos; e a última, ao objeto da ação. Os atores podem ser instituições governamentais, organizações sociais e capitais privado, ou todos juntos associados em rede sociotécnica, na transversalidade dos campos. Sendo que os processos são definidos por verticalidades e horizontalidades para a tomada de decisão política. E os objetos são considerados em suas diferentes categorias como: políticas sociais, culturais, ambientais, criação de emprego e renda, para citar as mais importantes.

O ponto de inflexão da proposta reconhece uma tensão conceitual entre planejamento urbano e políticas públicas. O planejamento urbano é um campo que se refere à capacidade de pensar o futuro do espaço, quando se valoriza o instrumento de plano diretor, dentro do qual se estabelece uma hierarquia que contempla a dimensão material, aquela que é produzida pela dimensão econômica. Quando nos referimos à política pública, estamos falando de programas de ação que vão além da dimensão visível e tangível do espaço, para examinar sua complexidade física e social. A proposta analítica é ir além da dimensão econômica e da intervenção do poder burocrático, para compreender a complexidade espacial como resultante também da dimensão relacional entre as pessoas e os grupos sociais aos quais elas pertencem. Isso significa que devemos examinar suas múltiplas dimensões, quer seja instrumental quer sejam relacional, material e imaterial, tangível e intangível.

3 A política publica é uma ação que se realiza pela sociedade política e pela sociedade civil por meio de estratégia, projeto e prática cotidiana através das quais se transforma 
o mundo social e material em todas as suas formas (GRAMSCI, 1984). No debate do campo podemos ler dois posicionamentos: um que reconhece o exercício da política de estado (LENIN, 1986; POULANTZAS, 1979; CASTELLS, 2000) e o outro que reconhece a ação prática (ARENDT 1992, 1993, 1994; LEFEBVRE, 1987; CERTEAU, 1994; SANTOS, 1994, 1998; RIBEIRO, 2001, 2005, 2007) dos sujeitos no cotidiano, no sentido de realizar o desígnio de alcançar o progresso social. Para os primeiros, isso é possível quando se considera a prerrogativa da sociedade política que tem o poder de alcançar condições necessárias para o desenvolvimento, enquanto para os segundos se reconhece a ação prática dos sujeitos políticos, para o alcance de mais equidade e justiça social.

4 Podemos dividir o debate em duas interpretações, uma primeira que valoriza as condições objetivas e outra, as condições subjetivas. Esse debate é importante, porque muitas vezes se confunde política publica com a política que emana do Estado, compreendido como sociedade política e governo dos funcionários, omitindo e minimizando a sociedade civil. É preciso estar alerta, para não confundir Estado com governo dos funcionários (COUTINHO, 1998). A nossa proposta analítica considera tanto as condições objetivas como as subjetivas, elas formam uma totalidade complexa que exige as duas interpretações simultaneamente, para conduzir a compreensão das múltiplas dimensões do processo espacial. E para tanto ler: objetos, fluxos e ações, como propõe Milton Santos $(1994,1998)$.

5 Nesse sentido, importa identificar as práticas políticas que emanam de todas as formas de organização da sociedade política e da sociedade civil, quando os atores são reconhecidos por sua capacidade de organizar uma ação em benefício de coletivos que compõem o espaço público. Gramsci (1984) permite entender, portanto, a esfera pública como um espaço de mediações entre os diferentes atores do tecido social, para além da separação entre organizações governamentais e instituições da sociedade civil. Por isso, a importância das redes sociotécnicas que permitem mediações tecnológicas e interações sociais que são capazes de produzir transversalidades nas diferentes dimensões das instituições e da existência social.

6 Esses atores são reconhecidos como: corporações internacionais, organizações governamentais em todas as escalas de governo - ministérios, secretarias de estado, prefeituras - e da sociedade civil - ONGS, OSCIPS, movimentos sociais, pessoas e tantas outras. A pesquisa proposta nesse projeto tem por objetivo reconhecer que existem redes sociotécnicas que associam corporações internacionais, governo em suas diferentes escalas, capitais privados e que atuam e, defesa de interesses globais, e outras redes sociotécnicas que associam atores organizações não governamentais, instituições de governo, capitais privados e pessoas para atuar em defesa do bem comum. O objetivo é fazer um mapeamento do que está acontecendo de mais importante na cidade do Rio de Janeiro, a fim de permitir a identificação, análise e avaliação de políticas públicas, as redes sociotécnicas que as organizam, e o seu resultado no que concerne à coesão social e as mutações que transformam as formas de organização do espaço da cidade. A pergunta pode ser enunciada:

7 Como, por quem e para quem é produzida a política publica no espaço urbano do Rio de Janeiro no contexto da globalização?

8 Para responder a essa pergunta, o programa de pesquisa está estruturado em dois eixos: Eixo 1: Rede global de dominação; Eixo 2: Rede de indignação.

9 Os eixos estão entrelaçados: o primeiro está dedicado a analise da política pública, associada aos mega eventos na cidade do Rio de Janeiro. Quando se analisa as redes 
sociotécnicas dedicados a transformar o Rio de Janeiro numa cidade do território global. O segundo eixo tem por objetivo analisaras políticas publicas que emanam de baixo para cima e representam a indignação frente a política de cima. É nosso objetivo maior: identificar, mapear, pensar, analisar, avaliar, compreender e divulgar os atores, processos, fatos e espaços do principal conflito no contexto da globalização.

10 A Internet possibilita novas formas de conectividade entre as nações, as cidades e as pessoas no mundo; transforma as trocas objetivas e subjetivas; possibilita a interação entre as nações; e potencializa a formação de um espaço social aterritorial e atemporal. o desafio desse eixo é examinar essa possibilidade: compreender que a inovação tecnológica aumenta a capacidade humana de organização e interação, possibilitada formas alternativas de conectividade que definem novas identidades sociais. Resta ainda questionar suas possibilidades de contemplar o bem-estar social. A proposta, portanto, examina a utilização da tecnologia para a formação de redes sociais para o mal estar social e para o bem estar social.

11 Esse objeto está referido à transformação da interação social e ação coletiva, que resultam da invenção de tecnologias de informação e comunicação (TICs). A inovação tecnológica transforma os processos de comunicação redefinindo a coesão social, e as relações de poder no território. Esse posicionamento analítico é derivado da compreensão que reconhece o poder político como resultante da coesão entre os homens, porque cria os fios invisíveis de interlocução entre os homens, produz um sentido comum do mundo, e permite uma ação coletiva em direção a um objeto compartilhado de ação. O pensamento que associa o poder ao território compreende como a comunicação amplia a coesão social e transforma as possibilidades de ação no território.

12 Se partirmos de um ponto de vista que valoriza a rede sociotécnica podemos começar dizendo que ao dissecar as partes para entender o todo, é preciso descobrir o interior das redes, examinar suas formas invisíveis e altamente complexas. Elas têm peso e leis próprias, se constituem como unidades menores a compor as maiores por meio de suas inter-relações. O desafio é entender tais relações, nas quais existem estruturas e regularidades próprias, que fazem a cola entre as suas partes e que moldam e remodelam as redes capazes de fazer a coesão desses atores em beneficio de objetivos compartilhados. Se a identificação dos atores é muito importante, não menos o são os objetivos em torno dos quais eles atuam.

13 A pesquisa aqui apresentada se propõe a desvendar estratégias que definam as formas como elas são utilizadas, que, por um lado, podem ampliar seu poder de dominação, e, por outro, as possibilidades de libertação. Essa condição pode ser lida nas relaçães estabelecidas entre as redes que estão dedicadas a realizar a prosperidade social no lugar, e as redes dedicadas ao crescimento da acumulação econômica da rede global. Esse é o desafio maior da pesquisa: estudar como as redes se conectam e formam uma totalidade mais complexa que estrutura as novas formas de organização econômica, política e social, no momento em que são redefinidos os poderes sobre o espaço e se transforma o território.

14 A questão proposta para análise tem por objetivo compreender como se transforma a comunicação social pela mediação de tecnologias de informação e comunicação, e compreender como elas promovem a formação de redes sociotécnicas que ampliam as possibilidades de interlocução para além dos limites tradicionais de interação social. Elas possibilitam a formação de novos fóruns cívicos pela criação de espaços públicos 
virtuais. Constituem-se na emergência de um espaço de comunicação virtual de todos para todos, em comunicação contínua, são sujeitos coletivos que se auto-organizam em torno de objetivos compartilhados de ação (EGLER, 2007), definindo novas articulações entre diferentes atores - instituições, organizações, pessoas -, compondo um espaço de intercâmbio e negociação de conflitos e consensos. (SCHERER; 2008).

Elas se constituem no âmbito de campos, definidos por Bourdieu (1989), quando se reúnem os atores em torno de um modo compartilhado de pensar, de ser e de agir. Elas podem ser observadas em toda ação humana, quer seja no labor, no faber ou na ação, para usar as categorias propostas por Hannah Arendt. (1981). É preciso distinguir a ação humana para além da econômica, para descobrir a sua complexidade no labor, referido ao corpo biológico, no faber, reunida nas atividades econômicas, e na ação do sujeito criativo e criador.

16 A proposta é compreender que a ação só pode se realizar no espaço (RIBEIRO, 2011), e que as redes sociotécnicas ampliam a capacidade de ação humana no lugar. Essa analise deverá nos permitir compreender a natureza da ação em suas dimensões objetivas e subjetivas, os processos de compartilhamento e possibilidades de cooperação, para compreender a definição de formas alternativas de organização social e política.

\section{Eixo 1 \\ Rede global para megaeventos no lugar}

17 Na atualidade esta em curso política urbana para megaeventos, como a Copa do Mundo e Olimpíadas, para fazer essa investigação devemos observar como ela resulta da ação de uma rede de atores globais que associa comitês esportivos, grandes corporações nacionais e internacionais, governos em todas as escalas, agentes financeiros, e também organizações sociais. Essa rede tem por objetivo mover milhões de turistas para a cidade, sendo capaz de concretizar a estrutura móvel da globalização (EGLER, 2011). A investigação está focada no exame e destino dos investimentos realizados pelos diferentes atores que participam da rede e para analisar as transformações sobre estrutura econômica, a ação política e permitir a analise dos seus resultados sobre o espaço e sobre a vida dos moradores da cidade.

Para participar da rede de cidades globais, o governo do Rio de Janeiro passou a realizar políticas urbanas capazes de colocar a nossa cidade na competitividade do sistema global. O que podemos observar é a formação de uma rede de mega corporações dedicada ao desenvolvimento de grandes eventos imateriais, de forte conotação simbólica, dentre as quais os jogos esportivos. Nesse contexto as cidades ocupam lugar de destaque, nelas se produzem outras necessidades que conduzem a novas subjetividades, as quais redefinem as relações sociais, os corpos e as mentes.

19 No discurso oficial podemos ler a valorização do desenvolvimento da economia. A argumentação esta associada à capacidade de ampliar as operações de turismo, impactar a economia, ampliar a capacidade de valorização do capital e promover a ampliação do numero de empregos. Para gerar impactos positivos no desenvolvimento social, arrecadação municipal e na formação de uma opinião pública favorável a visitação da cidade pela divulgação, nacional e internacional, da marca Rio de Janeiro.

Quais são os atores que participam da rede da globalização das cidades, como eles se associam e quais são seus interesses? 
21 Para tanto, o desafio é examinar as relações que se estabelecem entre, política e economia no território, para encontrar na sua analise a compreensão associadas à enunciação política do discurso até a valorização imobiliária. Para tanto, podemos dividir a estratégia global em dois eixos principais: o primeiro dedicado à transformação física do espaço da cidade do Rio de Janeiro, e o segundo para ampliar a mobilidade global. No primeiro, tecno-esfera, é preciso identificar os atores que participam das redes globais: como por exemplo, de corporações, as estratégias da política urbana em diferentes níveis de governo, a valorização da construção de equipamentos para grandes eventos, a implementação do sistema de transportes para viabilizar a mobilidade global. No segundo eixo, psico-esfera observamos, a formação de atratores, como os megaeventos esportivos, que deverão atrair milhões de turistas e proporcionar um segundo eixo de valorização do capital das empresas associadas a mobilidade global, como empresas aéreas, rede hoteleira, localizadoras, agencias de turismo, e um grande numero de pessoas que trazem, mostram, acompanham os turistas em seu passeio pela cidade. Como é o caso das amigas de aluguel, que cobram para passear com os turistas pelas ruas do Rio de Janeiro.

Quer dizer é preciso identificar, localizar e analisar os equipamentos destinados à realização dos jogos esportivos e compreender os sistema de transportes que articula os seus equipamentos destinados Resulta em uma totalidade espacial fragmentada que exige um alto nível de mobilidade para o acesso aos seus equipamentos. Quando o plano começou, exista um debate na cidade, por um lado os arquitetos defendiam uma localização central e por outro lado, os políticos a sua fragmentação que resultava na descentralização. A segunda opção ganhou!!!.

23 Era preciso um plano para produzir a alta mobilidade espacial, e garantir o processo de valorização imobiliária contida na estratégia da causa. E ganhou a proposta descentralizada. Vocês podem imaginar os custos associados ao imenso investimento realizado na estrutura física do sistema de transporte, e os lucros realizados com a mobilidade que resulta desse investimento. Por outras palavras, se produz uma necessidade socialmente inútil, para ampliar o investimento do estatal, pago pelos moradores do Rio de Janeiro, para propiciar um lucro extraordinário para os atores da tecno-esfera e da psico-esfera, como escrito na obra de Milton Santos.

24 Além dos equipamentos e dos transportes,construir um cluster, em torno dos equipamentos, evitar a proximidade da violência nos territórios conquistados pelos atores globais. Para chegar a esse objetivo, as UPPS cumprem o papel de manter e reitera o apartheid, no caso dos moradores do Rio de Janeiro. Para isso, foram instaladas mais de 50 UPPS-, implementação de unidades de pacificação popular nos arredores dos equipamentos para garantir a pacificação dos territórios da globalização (Mapa 1).

25 Todos esses processos têm importantes efeitos sobre a cidade, e a vida dos seus habitantes, é muito, muito grave o que esta acontecendo. Primeiro podemos observar um processo de expulsão de moradores, comerciantes não globalizados e tradicionais na cidade. Basta um passeio pelo Rio, para observar os efeitos perversos do processo de destruição/construção do espaço urbano. A cidade foi transformada em um grande canteiro de obras, quando passa um trator sobre as pessoas e seus negócios em prol da defesa de interesses alheios ao lugar . A destruição do espaço do lugar em benéfico da formação de um não lugar. Nesse se ampliam as horas em transporte urbano para todos os grupos sociais, se removeu numero importante de habitações à revelia dos 
moradores, se fecharam grande numero de estabelecimentos comerciais não globalizados, escolas encerraram sua atividades ,a cidade parou durante a realização da Copa do Mundo, produzindo importantes perdas em todos as atividades comercias e industriais, o que o poder que associa economia e política, de cima para baixo, em defesa de interesses alheio às pessoas do lugar.

Mapa 1

Localização dos equipamentos olímpicos, dos projetos de transporte, das vias principais, das UPPs e das Zonas Olímpicas na cidade do Rio de Janeiro

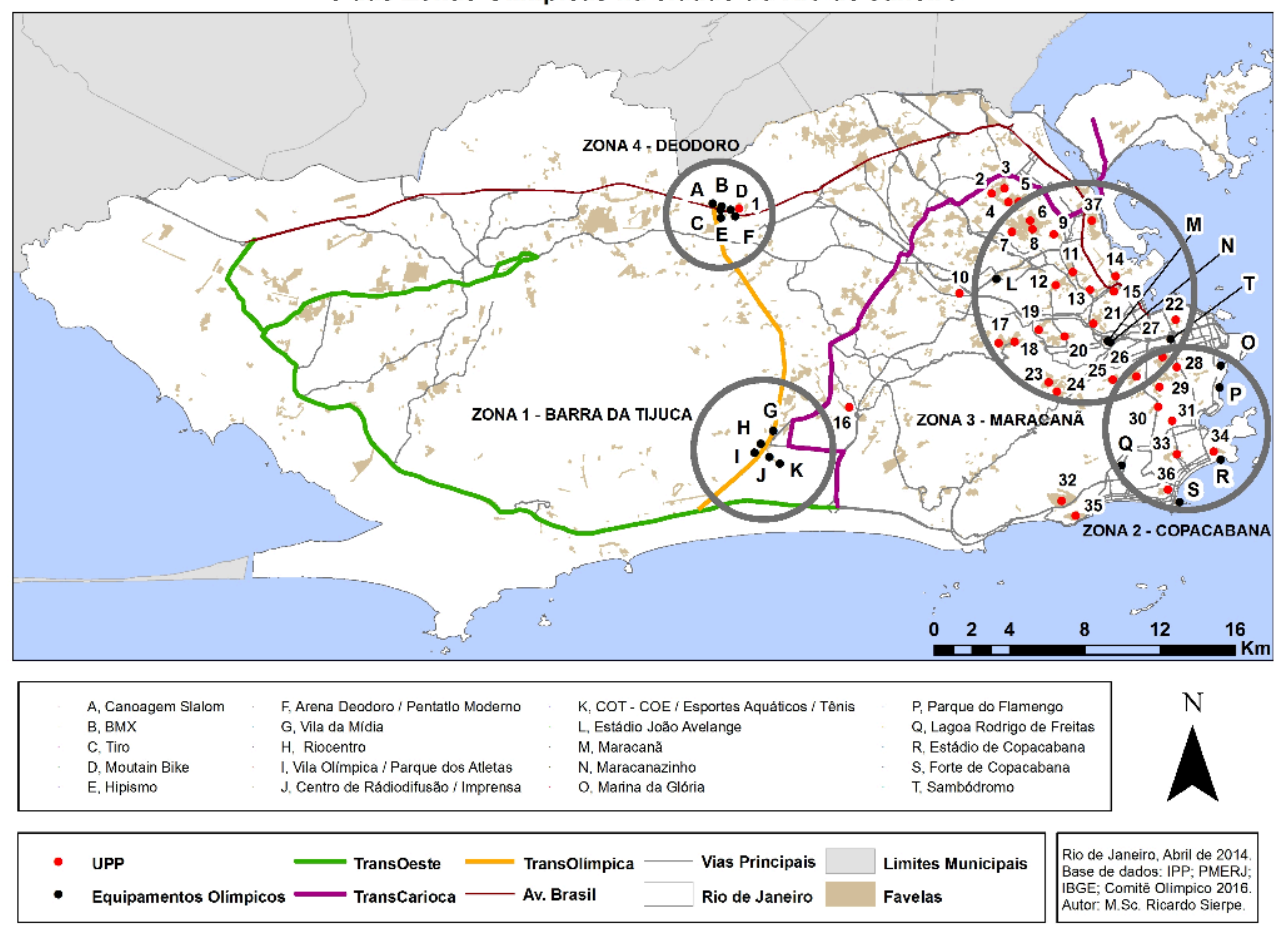

\section{Eixo 2}

\section{Rede de manifestação da indignação}

Não menos importantes são as redes de manifestação da indignação que revelam a existência de formas de organização social por mediação tecnológica de comunicação, quando se possibilita a emergência de formas de organização social de baixo para cima e formam uma institucionalidade política alternativa, essa é formada por uma totalidade que se origina da unificação de sindicatos, organizações da sociedade civil, organizações de profissionais, movimentos sociais, e associações de bairro. Organizam-se na transversalidade dos campos e atuam em objetos compartilhados de ação no espaço publico. Os fatos estão referidos a emergência das manifestações públicas que tomaram conta das ruas de cidades do Brasil, em junho de 2013.

Mais do que isso, a percepção em que era importante encontrar caminhos de investigação para conhecer o uso da internet por organizações sociais, nos conduziu para fazer a pesquisa sobre o tema (EGLER, 2007). Quando foi possível identificar um numero enorme de organizações da sociedade civil dedicadas ao tema de fazer política por mediação tecnológica. Nessa pesquisa foi possível identificar sete categorias de redes sociotécnicas que atuam na formulação de políticas públicas, são elas, por ordem 
de importância: proteção ambiental, integração social, criação de emprego e renda, saneamento básico, ação cultural, planejamento urbano. Para a realização da pesquisa foram estabelecidos procedimentos que tinham por objetivo representar a arquitetura das redes e reconhecer suas práticas nas políticas publicas. Nessa direção realizamos a pesquisa sobre as formas de comunicação que associavam um grande numero de atores das políticas publica A pesquisa teve importantes resultados, quando foi possível mapear as redes sociotécnicas, por objeto de ação. Quer dizer nos identificamos redes e seu campo de ação, como aquelas dedicadas a fazer a proteção do meio ambiente e ou outras dedicadas a fazer educação. Essa analise é muito importante para os desdobramentos de nossa pesquisa. Nessa pesquisa percebemos como a sociedade civil se organiza por campo, para a formulação, elaboração e execução de políticas públicas.

Esse foi o ponto de partida que conduziu nosso pensamento para compreender as formas de organização social nas manifestações de indignação nas ruas de cidades do Brasil. Esse eixo da pesquisa deve analisar os resultados alcançados com as formas de organização social de baixo para cima, para examinar o conflito entre redes, no contexto da globalização.

A reinvenção da democracia lida nas manifestações que tomaram conta das ruas no Brasil nos obriga a pensar, perguntar e analisar:

Como compreender a explosão da indignação coletiva lida nas manifestações de rua?

Como o Estado responde para a indignação expressa na ação coletiva?

Qual é a institucionalidade que esta redefinindo a política?

O que nos permite revelar as formas de organização de poder que emanam das formas contemporâneas de comunicação e coesão social, e que resultam da invenção de TICs. Para analisar e compreender os resultados alcançados com formas de organização política que se realizam por mediação tecnológica. Como já havia alertado Habermas, comunidades autônomas que se comunicam entre si. Para compreender as estratégias de enunciação de um discurso político alternativo que se dirige contra a política de cima e contra a dominação. As redes de indignação estão fundadas numa organização política que reúne sob numa mesma rede, todas as formas de organização política da sociedade civil. $\mathrm{O}$ que resulta em formas nunca antes imaginadas de formar um coletivo que atua no espaço publico para o enfrentamento dos sempre crescentes problemas sociais no Rio de Janeiro.

As instituições tradicionais estão fundadas nas relações verticais de poder, delegadas a um só homem a responsabilidade de decisão sobre a concepção e as práticas de ação política - nas relações verticais, os de "cima" mandam-nos de "baixo", que devem obedecer. Quando os "mais" - aqueles que ocupam uma posição na escada superior maltratam aqueles das escalas inferiores, são estabelecidas relações de dominação e de apropriação. Essa estrutura de poder tradicional está fundada na compreensão do domínio sobre o conhecimento e da capacidade de tomada de decisão que responde pelo conhecimento que legitima o poder (PUTNAM , 2002).

Para identificar os atores da ação, a metodologia observada foi ir às ruas, e participar das manifestações. Quando chegamos à Cinelândia, na grande passeata de junho de 2013. O primeiro grupo de jovens que encontramos foi de teatro, eles estavam se maquinado e se fantasiando. Ao poucos foram chegando os grupos, com faixas, com cartazes, vestidos de terno ou de palhaços, com mochilas e sem mochila, jovens e 
adultos, homens, mulheres e crianças, trabalhadores e elite, professores e estudantes, todos.

Essa percepção é importante por que já não era uma manifestação fabril, de operários em busca de melhores salários, também não era uma passeata organizada por uma associação de moradores para a ampliação de transportes urbanos, ou pela defesa de melhores condições de habitação. È mais do que isso, é todos contra tudo.

Para avançar era preciso observar quem são todos? E o que é tudo?

Para dar conta dessa interrogação, a metodologia foi fotografar os cartazes que os manifestantes portavam, para ler o discurso, vejam os resultados:

Os cartazes foram classificados por categoria e o mais eloquente pode ser atribuído a um discurso contra os políticos de cima, ao mesmo tempo foi possível revelar um discurso critico contra a política urbana, também foi emocionante ler sobre o valorização da identidade popular e o poder da interação social. O trabalho de unificação do discurso se completa com as reivindicações para melhores condições de vida na cidade:

Ver, ler e analisar as manifestações de rua foi um processo que nos obrigou a repensar a ação política. Podemos começar para compreender a ação coletiva no espaço publico pela indignação, como já havia percebido Castells (2013), trata-se de uma manifestação política de baixo que representar a resistência social para uma ação indigna da política de cima.

41 Sua importância esta associada ao significado em que se compreende o poder como a capacidade de agir coletivamente. Trata-se de analisar as transformação das relações de comunicação na política, e observar como as tecnologias de informação e comunicação, possibilita a formação de redes sociotécnicas que abrem a possibilidade de constituição de um espaço de enunciação coletiva, amplia as possibilidades de interlocução para além dos limites tradicionais de interação entre as organizações sociais. Para melhor explicar essa coisa que estamos percebendo, vale a pena fazer uma analise na relação dos espaços de comunicação das formas de organização política que se estabelece ao longo da história. Vamos pensar nas organizações operárias e nos seus espaços de comunicação. No urbano do nascente capital industrial, os espaços estão associados ao mundo da produção e consumo, fábrica e vila operária. Nesse contexto, se realiza a organização política nos sindicatos, a comunicação nas assembleias. De todos para todos, ao vivo.

No Estado do Bem Estar social os movimentos sociais faziam oposição ao Estado, para reivindicar melhores condições de existência no espaço urbano. Nesse contexto o campo dos estudos espaciais interroga sobre a natureza dessas formas de organização, havia sempre uma interrogação sobre como fazer a sua analise. Naquele momento histórico a pergunta interrogava sobre a condição de movimentos sociais, que acontecia em sobre o espaço urbano e não estava associada a uma reivindicação econômica.

Nesse contexto a política se complexifica quando observamos a ampliação dos atores da enunciação, dos objetos e do debate político, para além dos sindicados e partidos políticos. Nesse, assistimos ao exercício de uma ação social em conflito com o Estado. Os movimentos exigiam melhorias de condições de existência social no espaço urbano. Seus resultados foram amplamente analisados pelas ciências humanas naquele contexto histórico. 

além do federal.

Esse retorno na história da episteme das ciências humanas ajuda a compreender a dificuldade para se enfrentar a analise de novas formas de organização política. No contexto da globalização, a invenção de novas tecnologias de comunicação e de informação nos permite afirmar que elas possibilitam a articulação de um grande numero de organizações políticas. Quando os grupos sociais presenciais passam a dispor de ferramentas que possibilitam a comunicação na transversalidade das organizações, e permitem a organização de todos para todos, em rede sociotécnica.

Na pesquisa de campo foi possível identificar um entrelaçamento entre atores políticos na transversalidade de todas as identidades políticas, sociais e locais. Como movimentos sociais, associações de moradores, grupos de arte, músicos, estudantes,professores, advogados, amigos todos juntos contra a política do governo.

A invenção de tecnologia de informação e comunicação - TICs produz um espaço digital de fluxos de comunicação em tempo real, no qual emergem formas alternativas de resistência social. Forma-se um espaço complexo que reúne numa mesma totalidade vital + virtual. Transforma a política urbana e conduz para novos conteúdos das lutas sociais. Trata-se de compreender a importância da ação política das classes populares e as formas alternativas de institucionalidade política que se anuncia nas redes sociotécnicas. $\mathrm{O}$ desfio é realizar a analise para desvendar as formas de associação dos atores que participam dos conflitos urbanos, quando se considera a radicalização da democracia, como modelo político, para criar um espaço publico na formação do consenso (ARENDT, 1981; 1994) e conduzir para coesão social, em busca do exercício de uma ação libertária e criativa para o alcance da justiça no direito à cidade.

Para avançar na nossa demonstração devemos observar os resultados políticos alcançados pelas mobilizações de junho de 2013. A primeira medida tomada pela presidente Dilma esta referida às passagens de transporte público, quando foi criado um Conselho Nacional de Transporte Público no qual participam moradores e sociedade civil . Ao mesmo tempo foi considerada a desoneração de PIS e COFINS para o diesel de ônibus e para a energia elétrica de trens e metrôs. Considerou que tanto a desoneração quanto o Conselho poderiam ocorrer a nível estadual, municipal ou metropolitano,

No que se refere á reforma política e combate à corrupção, foi proposta a criação de um plebiscito para que uma assembleia constituinte exclusiva fosse criada. Também, pediuse que os governos fizessem o mais rapidamente possível a implementação da Lei de Acesso à Informação, e reconhecesse a corrupção dolosa como crime hediondo, se comprometendo a trabalhar pelo reconhecimento político.

Para responder para as reivindicações de natureza política, ela revela a aceleração dos investimentos já contratados para construção de UPAs, UBS e hospitais e ampliação do sistema que troca dívidas de hospitais filantrópicos por mais atendimentos. Ao mesmo tempo a presidente Dilma, defende uma política de saúde publica, em que médicos deveriam receber maiores incentivos para trabalhar nas regiões mais pobres e remotas, e que caso isso não resolvesse, que médicos estrangeiros fossem levados para esses lugares, exclusivamente para o SUS.

Falou que este aspecto enfrentaria oposição dos médicos, mas disse querer deixar claro que não é algo hostil e desrespeitoso à classe médica, mas uma ação limitada e emergencial, que o Brasil é um dos países que menos emprega médicos estrangeiros e que de qualquer forma a saúde dos brasileiros deve prevalecer sobre quaisquer 
interesses. Disse que iria ainda tomar uma série de outras medidas para melhorar as condições de trabalho nos hospitais públicos.

51 Para a educação prometeu $100 \%$ dos royalties do petróleo. E para a responsabilidade fiscal se compromete a manter as medidas de estabilidade econômica e controle da inflação proteger o Brasil da crise mundial ${ }^{1}$.

52 É muito difícil para as pessoas pensarem em termos de fenômenos coletivos, por que a tradição do pensamento político reconhece estruturas políticas em que o poder emana de cima para baixo e se realiza por delegação. Estamos falando de formas alternativas de organização política em rede sociotécnica. Rede sociotécnica é um coletivo autoorganizado, é a unificação de grupos sociais de identidade diferenciada, se comunicam entre si por tecnologia digital. Quando passa a formar um único organismo que se move em direção da defesa de interesses compartilhados (EGLER, 2007,2011) têm peso e leis próprias, se constituem como unidades menores que compõem as maiores através de suas inter-relações (ELIAS, 1988). Produz coesão social e permite a emergência do poder da ação coletiva de estrutura horizontal, e de baixo para cima.

53 A emergência de ação política de baixo para cima está associada ao significado, imanente da evolução dos sistemas, emergir é fazer aparecer o que está em baixo para ocupar uma posição em cima. Em sua importante pesquisa Steven Johnson, demonstra como os organismos emergentes ficam mais inteligentes com o tempo e reagem de forma positiva às necessidades mutantes do seu ambiente (JOHNSON, 2003). Essa importante contribuição conduz a nossa reflexão a entender as leis da emergência no contexto de uma sociedade com alto poder de comunicação social, permite a formação de comunidades autônomas que se comunicam entre si. E se transforma a política no sentido de reinventar e radicalizar a democracia.

\section{Concluindo}

Para finalizar a nossa contribuição ao debate, foi possível observar como as tecnologias de informação transformam os processos de comunicação permitindo uma coesão de grupos sociais, para além do espaço vital. A digitalização do espaço permite formas de coesão para além das tradicionais formas de organização econômica e política.

As permitir a transversalidade entre campos, elas possibilitam a unificação da economia com a política e a ampliação do poder de dominação, mas ao mesmo tempo redefinem a articulação entre as organizações políticas de defesa do interesse coletivo. Quer dizer estamos diante de formas alternativas de organização política que redefinem o conflito, por um lado temos a rede de corporações e por outro lado a rede de indignação. $O$ conflito principal esta além das relações de oposição entre Capital e Trabalho, ou Estado e Movimentos Sociais, esta centrado na oposição entre rede de dominação global e rede de indignação social. 


\section{BIBLIOGRAFIA}

ARENDT, Hannah. A dignidade da política. Rio de Janeiro: Relume Dumará, 1993.

. Sobre a violência. Rio de Janeiro: Relumé Dumará, 1994.

. A condição humana. Rio de Janeiro: Relume Dumará, 1992.

BOURDIEU, Pierre. 0 poder simbólico. R.J.: Bertrand, 1998.

. A distinção. Critica social do julgamento. São Paulo: EDUSP; Porto Alegre: Zouk, 2007.

CASTELLS, Manuel. Redes de indignação e esperança: movimentos sociais na era da internet. Rio de Janeiro: Jorge Zahar, 2013.

COUTINHO, Carlos Nelson. Socialismo e democracia - a atualidade de Gramsci. In: AGGIO, Alberto (Org.). Gramsci: A vitalidade de um pensamento. São Paulo: Editora UNESP, 1998.

CERTEAU, Michel. A invenção do cotidiano. Petrópolis, Vozes, 1994.

EGLER, Tamara Tania Cohen. Redes e territórios. Relatório de pesquisa apresentado ao programa Cientista do Nosso Estado da Faperj, 2011. . (Org.). Ciberpólis: Redes no Governo da cidade. Rio de Janeiro: Editora 7letras, 2007. Direito e democracia. Entre facticidade e validade. Rio de Janeiro, Tomo I e II. RJ: Tempo Brasileiro, 1997.

HARDT, Michael; NEGRI, Antonio. Império. Rio de Janeiro: Record, 2001.

LEFEBVRE, Henri. A vida cotidiana no mundo moderno. Madrid: Alianza Editorial, 1984.

LENIN, Vladimir Ilitch. Estado e a revolução: o que ensina o marxismo sobre o Estado e o papel do proletariado na revolução /Vladimir Ilitch Lênin, São Paulo : HUCITEC, 1986

POULANTZAS, N. O Estado, o poder, o socialismo. Rio de Janeiro: Graal, 1980.

RIBEIRO, Ana Clara Torres. Por uma cartografia da ação: pequeno ensaio de método. Cadernos IPPUR/UFRJ, v. 15,16, p. 33-52, 2001.

RIBEIRO, Ana Clara Torres e SILVA, Cátia Antonia. Impulsos Globais e Espaço Urbano: sobre o novo economicismo. In: RIBEIRO, Ana Clara Torres (Org.). O rosto urbano da América Latina. Buenos Aires: Clacso, 2004.

RIBEIRO, Ana Clara Torres. Oriente negado: cultura, mercado e lugar. Cadernos PPG-AU/FAUFBA, v. II, p. 97-107, 2004.

SANTOS, Milton. Técnica, espaço, tempo: globalização e meio técnico-científico informacional. São Paulo, HUCITEC, 1994. Caps. I e II.

. A natureza do espaço. Técnica e tempo. Razão e Emoção. São Paulo: Hucitec, 1996.

SOUZA, Marcelo José Lopes de. O território: sobre espaço e poder, autonomia e desenvolvimento. In: CASTRO, I; GOMES, P; CORRÊA, R. (Orgs.). Geografia: conceitos e temas. Rio de Janeiro: Bertand Brasil. 


\section{NOTAS}

1. $24 / 06 / 2013$ - Dilma anuncia 5 pactos, disponível: http://noticias.terra.com.br/brasil/ politica/,c3576d53bbb6f310VgnCLD2000000dc6eb0aRCRD.html

\section{RESUMOS}

A questão proposta para analise nesse artigo é examinar o efeito da invenção de novas tecnologias de informação e comunicação e as potencialidades de sua organização em rede sociotécnicas na transformação da política. Isso para examinar os resultados alcançados com políticas que emanam de cima para baixo e comparar seus resultados com políticas que emergem de baixo para cima. Para compreender quais são os atores que se associam em rede, para conceber e implementar políticas e analisar os resultados alcançados sobre as condições de existência social na cidade. A pesquisa proposta tem por objetivo reconhecer e mapear as redes sociotécnicas que associam corporações internacionais, governo em suas diferentes escalas, capitais privados e os que atuam em defesa de interesses globais, e outras redes sociotécnicas que associam atores organizações não governamentais, instituições de governo, capitais privados e pessoas para atuar em defesa do bem comum.

The question proposed in this article is to examine the effect of invention of new information and communication technologies and its potential for the organization of socio-technical network in the transformation of politics. This is to examine the results achieved with top-down policies and compare its results with bottom-up policies. This is done in order to understand who are the actors that associate in network for designing and implementing policies and to analyze the results achieved on the conditions of social existence in the city. The proposed research aims to recognize and map the socio-technical networks involving international corporations, government on different scales, private capital that are operating for the defense of global interests, and other socio-technical networks linking actors and NGOs, government institutions, private capital and people that act in defense of the common good.

La cuestión propuesta para el análisis de este artículo es examinar el efecto de la invención de nuevas tecnologías de la información, las comunicaciones, y el potencial de su organización en red socio-técnica para la transformación de la política. Es para examinar los resultados logrados con las políticas que emanan de arriba hacia abajo y comparar sus resultados con las políticas que surgen de abajo hacia arriba. Para entender además que los actores que se asocian a la red es para diseñar e implementar políticas, y analizar los resultados obtenidos en las condiciones de existencia social en la ciudad. La investigación propuesta tiene como objetivo reconocer y mapear las redes socio-técnicas que involucran a empresas internacionales, los gobiernos, a diferentes escalas, de capital privado y actuar en defensa de los intereses globales y otras redes socio-técnicas que vinculan actores ONG, instituciones gubernamentales, de capital y los particulares que actúen en defensa del bien común.

Cet article analyse les effets de l'invention de nouvelles technologies de l'information et de communication et les potentialités de leur organisation en réseaux sociotechniques afin de transformer la politique. On veut évaluer ces effets par rapport aux politiques qui se déploient de haut en bas et comparer leurs résultats avec des politiques qui se déploient d'en bas en haut. On 
vise à reconnaître les acteurs qui s'associent en réseaux pour concevoir et accomplir certaines politiques, en analysant les résultats et ses rapports avec les conditions d'existence sociale dans la ville. En outre, on doit identifier les réseaux sociotechniques responsables pour associer des corporations internationaux et des gouvernements à différentes échelles, ainsi que des capitaux privés qui marchent à la défense des intérêts mondiaux et d'autres réseaux sociotechniques dont la finalité c'est la défense du bien commun.

\section{ÍNDICE}

Keywords: socio-technical netwook, politics, actors, technology, comunicación

Palavras-chave: rede sociotécnica, política, atores, tecnologia, comunicação

Palabras claves: socio-técnicas red, política, atores, tecnología, comunicación

Mots-clés: réseaux sociotechniques, politique, acteurs, technologie, communication

\section{AUTORES}

\section{TAMARA TANIA COHEN EGLER}

Doutora em sociologia - Universalidade de São Paulo, Professora no Instituto de Pesquisa e

Planejamento Urbano e Regional, Universidade Federal do Rio de Janeiro IPPUR-UFRJ, 1B CNPq, Cientista do Nosso Estado Faperj. tamaraegler@uol.com.br

\section{FABIANA MABEL DE OLIVEIRA}

Doutoranda em Urbanismo, PROURB/UFRJ, Mestre em Arte e Tecnologia, UNB, vicecoordenadora do Laboratório Espaço, Instituto de Pesquisa e Planejamento Urbano e Regional, Universidade Federal do Rio de Janeiro

\section{LUCAS TRAJANO}

Estudante de geografia. IGEO / UFRJ, bolsista de IC no laboratório Espaço. Instituto de Pesquisa e Planejamento Urbano e Regional, Universidade Federal do Rio de Janeiro 